\title{
Personal Space of Small Mobile Robot Moving towards Standing or Sitting Elderly Individuals
}

\author{
Masako Sakai ${ }^{1}$ and Akiko Watanabe ${ }^{2}$ \\ 1. Graduate School of Science and Technology for Future Life, Tokyo Denki University, Tokyo 120-8551, Japan \\ 2. Department of Architecture, Tokyo Denki University, Tokyo 120-8551, Japan
}

\begin{abstract}
Recently, Japan has experienced a low birthrate and an aging population. The development of communication robots, such as cleaning and a care-giver robot, has been progressing. Care-giver robots provide daily assistance, including contacting emergency services. This study is part of the "study on planning techniques of living space in harmony with robots", and focused on the elderly. Minimum distance was the subjects felt "I do not want any more approached". Subjects were 21 elderly persons (eight males and thirteen females), aged 66-86 years. The experimental room was an assembly room in a public accommodation $(14 \mathrm{~m} \times 6.5 \mathrm{~m})$. The small mobile robot used in this experiment was external form dimensions of $120 \mathrm{~mm}(\mathrm{~W}) \times 130 \mathrm{~mm}(\mathrm{D}) \times 70 \mathrm{~mm}(\mathrm{H})$. In this experiment, considering the personal space as the small mobile robot is watching robot without support function for person. The robot moved toward standing or sitting subjects at constant velocities from a distance $5 \mathrm{~m}$ apart. Research factors are 5 angles $\left(0^{\circ}, 45^{\circ}\right.$, $90^{\circ}, 135^{\circ}$ and $\left.180^{\circ}\right)$ and 2 speeds $(0.08 \mathrm{~m} / \mathrm{s}$ and $0.24 \mathrm{~m} / \mathrm{s})$.
\end{abstract}

Key words: Small mobile robot, personal space, elderly persons, living space.

\section{Introduction}

Recently, Japan has experienced a low birthrate and an aging population, resulting in an increase in the elderly who are living alone [1]. In an aging society, a decrease in working population increases the burden of caregivers. In the robot industries, the development of communication robots, such as cleaning and care-giver robots has been progressing, so the authors can find it daily in people's living space. Care-giver robots provide daily assistance, including contacting emergency services. Considering these backgrounds, planning living spaces that are in harmony with robots are necessary to clarify the relationship between robots and the elderly.

\section{Thesis-Related Research}

Robotics research in the field of architectural planning, has been promoted by the "research space for the coexistence of humans and robots" [2-4],

\footnotetext{
Corresponding author: Masako Sakai, graduate student, research field: architecture planning. E-mail: masako1989@gmail.com.
}

Waseda University. In addition, Nakazima and Sato $[5,6]$ study distance of robot and human in "Personal distance against mobile robot". In addition the authors make a survey of the personal distance against robot for adults, in "study on planning technique of living space harmony with robots” [7] yet.

\section{Research Objectives}

This study is part of the "study on planning techniques of living space in harmony with robots", and focused on the elderly. Study used a small mobile robot and investigated the distance between an elderly person and the robot. The minimum distance was when the participants said that they did not want the robot to come any closer.

\section{Methods}

\subsection{Experiment Summary}

The experiments were conducted over a ten-day period from August 1 to September 7, 2011. Subjects were 21 elderly persons (eight males and thirteen 
females) aged 66-86 years (Fig. 1), but there were several people who were hard of hearing. The experimental room was an assembly room in a public accommodation (Chiyoda ward senior center) (14 $\mathrm{m} \times$ $6.5 \mathrm{~m}$ ) (Fig. 2). Two positions of the participants were investigated, standing (Experiment 1) and sitting in a chair (Experiment 2), which are considered the most common positions in daily life. Distance was measured in 20 patterns ( 2 speeds, $0.08 \mathrm{~m} / \mathrm{s}$ and 0.24 $\mathrm{m} / \mathrm{s}$, each from 5 angles, $0^{\circ}, 45^{\circ}, 90^{\circ}, 135^{\circ}$ and $180^{\circ}$ ) with the experimental conditions listed in Table 1. A

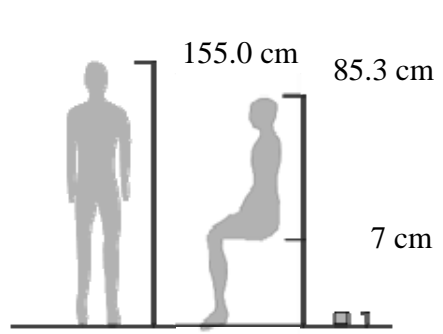

questionnaire survey was also conducted before and after the experiments. Fig. 3 shows experiment scenery.

\subsection{Specifications of Small Mobile Robot}

The small mobile robot used in this experiment was a two-drive type with dimensions of $120 \mathrm{~mm}(\mathrm{~W}) \times$ $130 \mathrm{~mm}(\mathrm{D}) \times 70 \mathrm{~mm}(\mathrm{H})$. The robot could only move at two speeds. The robot could be remotely controlled from a distance of $5 \mathrm{~m}$. Figs. 4 and 5 show schematics of the robot.

Fig. 1 The height of the robot and the human, subject average.

Average age 79.4 years;

Average height $155.0 \mathrm{~cm}$;

Sitting height $85.3 \mathrm{~cm}$

(Sitting height was determined on the basis of approximate body dimensions $(155.0 \times 0.55))$

Height small mobile robot $7 \mathrm{~cm}$.

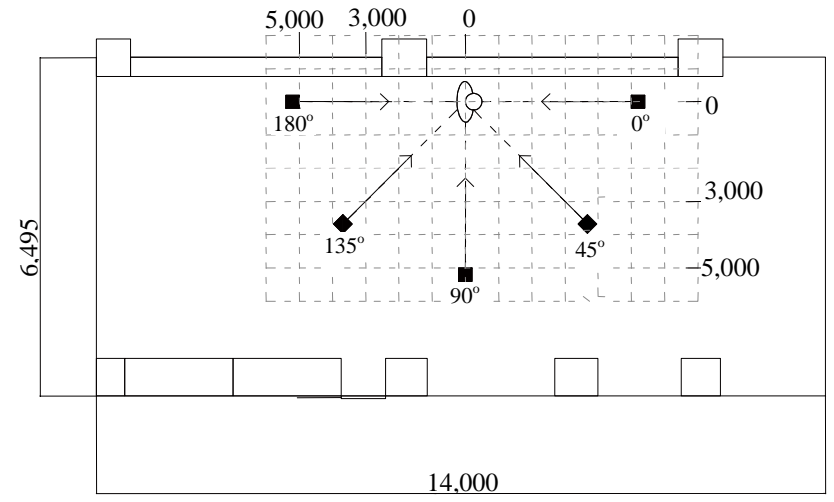

Fig. 2 Experiment place (unit: $\mathbf{c m}$ ).

Table 1 Setting the experimental conditions.

\begin{tabular}{llllll}
\hline Speed & \multicolumn{5}{c}{ Angle } \\
\hline $0.08 \mathrm{~m} / \mathrm{s}$ (low) & $0^{\circ}$ & $45^{\circ}$ & $90^{\circ}$ & $135^{\circ}$ & $180^{\circ}$ \\
$0.24 \mathrm{~m} / \mathrm{s}$ (medium) & $0^{\circ}$ & $45^{\circ}$ & $90^{\circ}$ & $135^{\circ}$ & $180^{\circ}$ \\
\hline
\end{tabular}

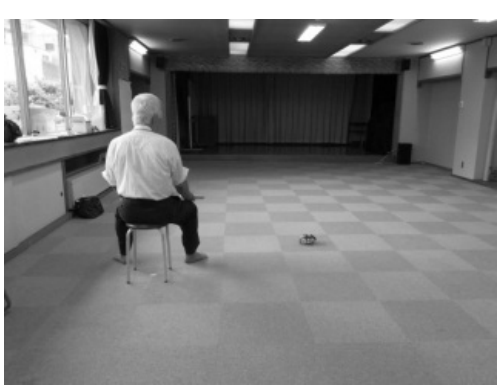

Fig. 3 Experiment scenery.

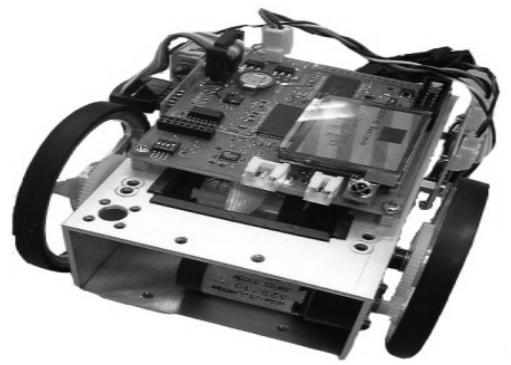

Fig. 4 Small mobile robot. 


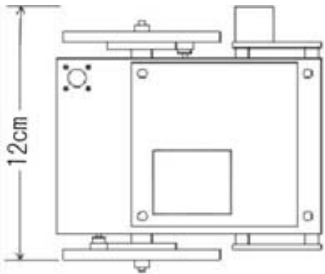

Top view

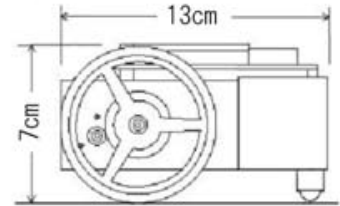

Side view

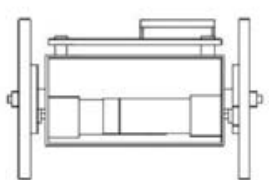

Front view

Fig. 5 Schematics of the robot.

\section{3 Experimental Conditions}

In this experiment, considering the personal space as the small mobile robot is watching robot without support function for person. The small mobile robot approached standing and sitting participant from the right at 5 angles at a distance of $5 \mathrm{~m}$, and stop the robot when the participant feels "do not come near". Distance was measured from the center of the plantar surface of the participant to the front of the small mobile robot. The measurement range was from the right side of the participant. The participants were given the following instructions:

(1) Measure the distance when you do not want the robot to come any closer;

(2) Measurements are 5 directions, 2 speeds and 2 positions, total 20 patterns are practiced;

(3) During measurement, avoid changing the direction of the body and please face the robot.

\section{Results of Experiment 1}

\subsection{Measure Distance}

Table 2 shows the average of measure distance related each speed of the subject. It was determined the standard deviation to indicate the overall variability because the data have individual variations. Fig. 6 shows the average value.
As shown in Table 2, the average measure distance at $0.08 \mathrm{~m} / \mathrm{s}$ was between $83.6-97.9 \mathrm{~cm}$ and that at 0.24 $\mathrm{m} / \mathrm{s}$ it was between $90.2-106.1 \mathrm{~cm}$.

\subsection{Tendency of Measure Distance for Angle and Speed}

In Fig. 6, subjects were taken longer distance in the $45^{\circ}$ and $135^{\circ}$, therefore there is a tendency to take a distance in oblique direction. Compare of measure distance in two speeds shows that the distance at $45^{\circ}$ and $0^{\circ}$ of $0.08 \mathrm{~m} / \mathrm{s}$ was shorter and difference of 10 $\mathrm{cm}$.

\subsection{Verification of Interaction in Approaching Angle and Speed}

It is analyzed the tow-way layout to verify what kind of effect angle and speed give to personal space. Table 3 shows the result of variance analysis. It was not found significant difference in the interaction between angle and speed, from $F(4,200)=0.117$, and significant probability 0.976 . Consideration of main effect, main effect of approaching angle $F$ (4, $200)=0.184$, and significant probability is 0.946 . Main effect of speed is $F(1,200)=0.060$, and significance probability is 0.806 . Therefore, angle and speed effect is not found at personal space of standing position.

Table 2 Average of personal space each speed table in standing (unit: $\mathbf{c m}$ ).

\begin{tabular}{lccccc}
\hline \multirow{2}{*}{ Speed } & \multicolumn{5}{c}{ Angle } \\
\cline { 2 - 6 } & $0^{\circ}$ & $45^{\circ}$ & $90^{\circ}$ & $135^{\circ}$ & $180^{\circ}$ \\
\hline $0.08 \mathrm{~m} / \mathrm{s}$ & 83.6 & 97.9 & 95.5 & 96.2 & 95.2 \\
$0.24 \mathrm{~m} / \mathrm{s}$ & 95.6 & 106.1 & 92.5 & 96.1 & 90.2 \\
Average & 89.6 & 102.0 & 94.0 & 96.2 & 92.7 \\
Standard deviation & 67.4 & 72.7 & 68.0 & 72.2 & 64.3 \\
\hline
\end{tabular}




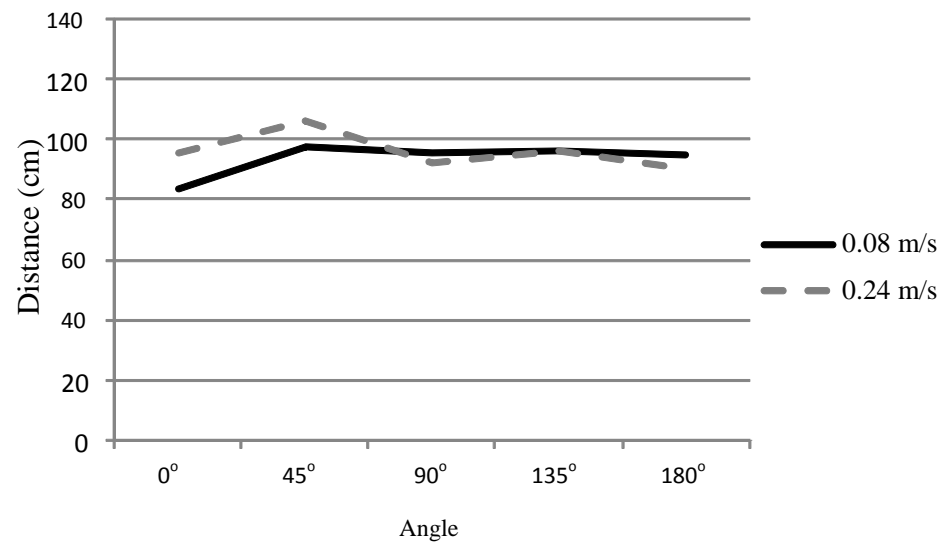

Fig. 6 Average graph of personal space of each speed at standing.

Table 3 Test of main effect while standing.

\begin{tabular}{lrrrllr}
\hline Fluctuation factor & Sum of squares & Degree of freedom & Mean square & F-ratio & \multicolumn{2}{c}{ Significance probability } \\
\hline Angle & $3,590.967$ & 4 & 897.742 & 0.184 & 0.946 & not significant \\
Speed & 293.585 & 1 & 293.585 & 0.06 & 0.806 & not significant \\
Angle $\times$ Speed & $2,277.984$ & 4 & 569.496 & 0.117 & 0.976 & not significant \\
Error & $973,268.806$ & 200 & $4,866.344$ & & \\
Total & $979,431.342$ & 209 & & & \\
\hline
\end{tabular}

\section{Results of Experiment 2}

\subsection{Measure Distance}

Table 4 shows the average of measure distance related each speed of the subject. Fig. 7 shows the average value. As shown in Table 4, the average measure distance at $0.08 \mathrm{~m} / \mathrm{s}$ was between $85.3-109.9 \mathrm{~cm}$ and that at $0.24 \mathrm{~m} / \mathrm{s}$ was between 81.5-106.7 cm.

6.2 Tendency of Measure Distance for Angle and Speed

In Fig. 7, measure distance in case of $0^{\circ}-45^{\circ}$, $135^{\circ}-180^{\circ}$. become longer, and in the case of $45^{\circ}-135^{\circ}$ shorter. Compare of measure distance in two speeds that there is hardly difference.

6.3 Verification of Interaction in Approaching Angle and Speed

Two-way layout analysis of variance is done as well as the Experiment 1. Table 5 shows the result of variance analysis. It was not found significant difference in the interaction between angle and speed, from $F(4,200)=0.039$, and significant probability 0.997. Consideration of main effect, main effect of approaching angle $F(4,200)=1.081$, and significant probability is 0.367 . Main effect of speed is $F(1,200)$ $=0.158$, and significance probability is 0.691 . Therefore, angle and speed effect is not found at personal space of sitting position.

Table 4 Average of personal space each speed table in sitting (unit: $\mathbf{c m}$ ).

\begin{tabular}{lrrrcc}
\hline \multirow{2}{*}{ Speed } & \multicolumn{5}{c}{ Angle } \\
\cline { 2 - 6 } & $0^{\circ}$ & $4^{\circ}$ & $90^{\circ}$ & $135^{\circ}$ & $180^{\circ}$ \\
\hline $0.08 \mathrm{~m} / \mathrm{s}$ & 104.5 & 109.9 & 93.3 & 85.3 & 96.3 \\
$0.2 \mathrm{~m} / \mathrm{s}$ & 106.3 & 106.7 & 89.8 & 81.5 & 87.0 \\
Average & 105.4 & 108.3 & 91.6 & 83.4 & 91.7 \\
Standard deviation & 69.6 & 76.4 & 60.1 & 59.2 & 54.4 \\
\hline
\end{tabular}




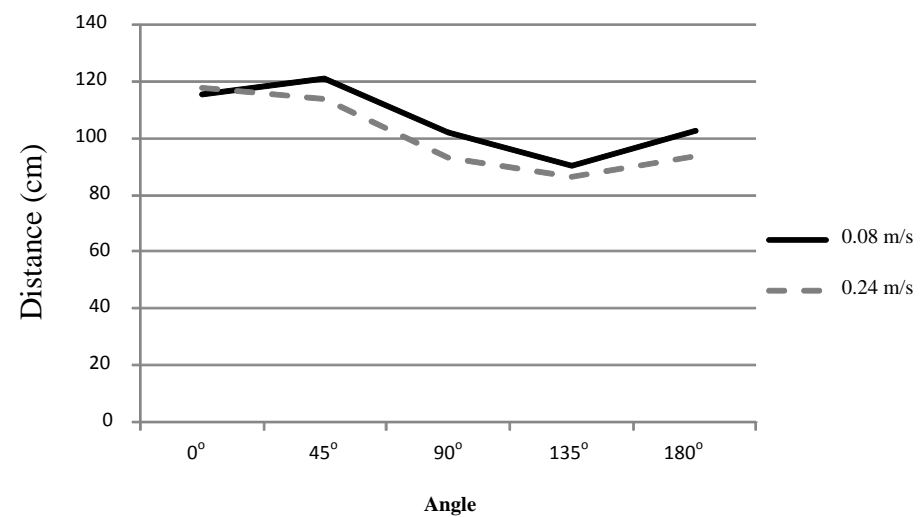

Fig. 7 Average graph of personal space of each speed at sitting.

Table 5 Test of main effect while sitting.

\begin{tabular}{lcccccc}
\hline Fluctuation factor & Sum of squares & \multicolumn{2}{c}{ Degree of freedom Mean square } & F-ratio & \multicolumn{2}{c}{ Significance probability } \\
\hline Angle & $18,366.628$ & 4 & $4,591.657$ & 1.081 & 0.367 & not significant \\
Speed & 672.145 & 1 & 672.145 & 0.158 & 0.691 & not significant \\
Angle $\times$ Speed & 658.044 & 4 & 164.511 & 0.039 & 0.997 & not significant \\
Error & $849,533.812$ & 200 & $4,247.669$ & & & \\
Total & $869,230.63$ & 209 & & & & \\
\hline
\end{tabular}

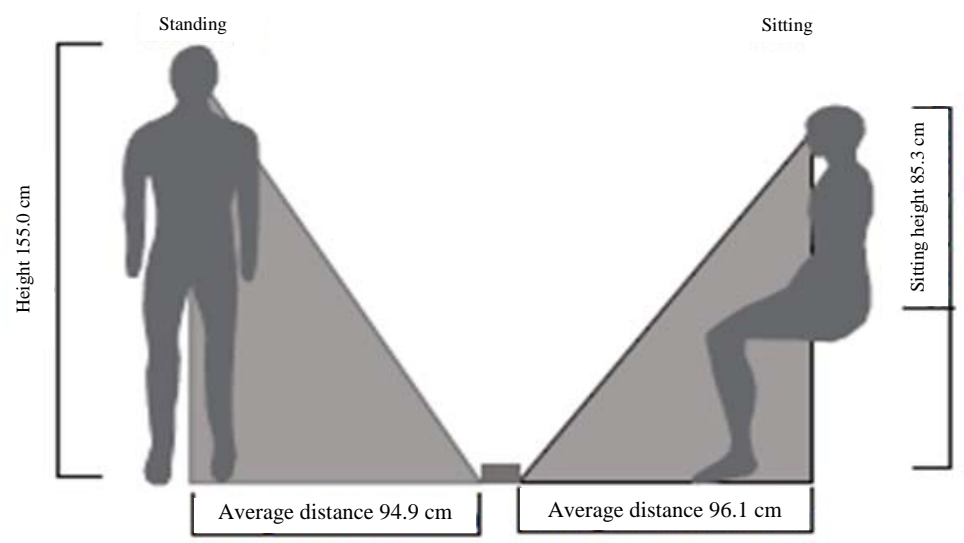

Fig. 8 Average distance of standing and sitting.

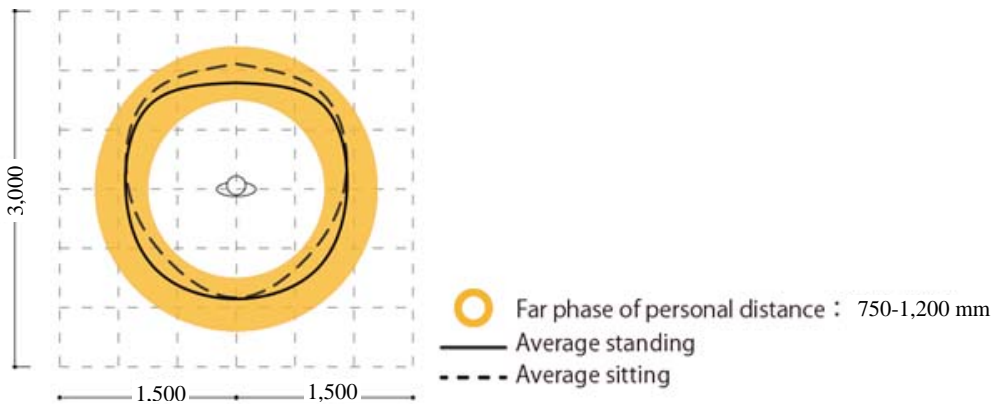

Fig. 9 Personal space for a small mobile robot.

\section{Consideration}

\subsection{Personal Space, Speed and Approach Angle}

In case of this experiment, it is found that the personal space was not influenced by the effect of approach angle and speed by interactive verification. However, in Experiment 1 (standing), the personal distance was shorter at $0^{\circ}$ at $0.08 \mathrm{~m} / \mathrm{s}$ (Fig. 4). It is 
thought that slow speed makes subject the approach limit distance becomes shorter without a fear. In Experiment 2 (sitting), the personal space was longer at $180^{\circ}$ (Fig. 7).

It is thought that the difficulty of seeing around $180^{\circ}$ made personal space longer.

\subsection{Relationship of Position and Personal Space}

The average distance at standing takes long distance than sitting. The distance of standing is 89.6 and 102.0 $\mathrm{cm}$ (average $94.9 \mathrm{~cm}$ ), and sitting is 83.4 and 108.3 $\mathrm{cm}$ (average $96.1 \mathrm{~cm}$ ) (Fig. 8). In comparison of position, $0^{\circ}$ to $90^{\circ}$ at sitting makes long distance and $90^{\circ}$ to $180^{\circ}$ at standing makes long one.

\subsection{Classification of Personal Space}

It is thought average of personal space, the distance of both standing and sitting are in the range of forward 75-120 cm according to Edward Hall "dimensional hidden" [8] (Fig. 9). The characteristic of this range is that "From the distance of hands touch to fingertip touch range, distance of possible private conversation". Therefore, the authors say that the small mobile robot can not approach to the distance of suggests close, but can expose in the range of hands touch. The authors think above results are affected by follows. Many elderly think crash makes no pain and have security and safety.

\section{Conclusions}

After this study the personal spaces toward to the small mobile robot were obtained four results:

(1) Personal space of standing subjects was shorter than sitting subjects;

(2) Elderly were tended to take a distance forward;

(3) The personal space for the small mobile robot, the large influence on speed and approach angle, but there is a little influence on the speed of standing subject and on the approach angle of the sitting subject;

(4) The calculated personal space from the experiments is as follows the distance phase of the "personal space" and "the range of from hand contact distance to fingertips touch, the distance of private conversation”.

\section{References}

[1] Aging Status of Chapter 1, Present Status and Trends of the Environment Surrounding the Figure of the Elderly Section 2, Family and Household of an Elderly, Cabinet Office, Elderly white paper version of 2011, 2011, pp. 13-17.

[2] A. Enta, H. Watanabe, T. Sano, K. Hayashida, A study of avoidable distance against robot, Journal of Architecture, Planning and Environmental Engineering 601 (2006) 81-85.

[3] K. Hayashida, A. Enta, Y. Yoshioka, M. Takahashi, Y. Sano, H. Watanabe, Comfortable distance between the man and the autonomy robot, Journal of Architecture, Planning and Environmental Engineering 651 (2010) 1133-1140.

[4] Y. Yousuke, M. Thakahashi, H. Watanabe, A. Enta, Y. Sano, K. Hayashida, Characteristic behavior in follow-walking to leading robots, Journal of Architecture, Planning and Environmental Engineering 75 (652) (2010) 1399-1406.

[5] K. Nakazima, H. Sato, Personal distance against mobile robot, Journal of Japan Ergonomics Research Society 35 (2) (1999) 87-95.

[6] K. Nakazima, H. Sato, Personal distance against mobile robot: Part 2-Older persons, Journal of Japan Ergonomics Research Society 35 (4) (1999) 253-258.

[7] M. Aoki, A. Watanabe, A study on the distances of an upright/char-sitting small mobile robot to male adult individuals, Journal of Architecture, Planning and Environmental Engineering 664 (2011) 1093-1100.

[8] E. Hall, The Hidden Dimension, Doubleday \& Company Inc., New York, 1966. 